\title{
MULTI LEVEL MARKETING DALAM PERSPEKTIF SYARIAH
}

\author{
Nur Dinah Fauziah, Sundari, Iis Ayu Agustina \\ Institut Pesantren KH. Abdul Chalim Mojokerto \\ Email: dina.fau@gmail.com; Sundarifreste89@gmail.com \\ iisayuagustina@gmail.com
}

\begin{abstract}
In reality, now MLM company have been many of the grown and well developed in the country and overseas. Even in indonesia that there is in publicly declared that MLM is in line with and get certification from the board of Dewan Syariah National Majelis Ulama Indonesia (DSN-MUI). Trading system the multilevel marketing (MLM) should be conducted by means of capture of a borrower that also functioned as consumers and member of the employers in the form of MLM. Islamic principal about the development of business systems that should be free of elements dharar (danger), jahalah (obscurity) and zhulm (hurt them or not fair with one party). Hence, the bonuses system has to be fair, did not wrong and not only benefits of the.Business also should be free of elements maysir (gambling), gharar (fraud), unlawful, interest rate, and false. So if we want to do business MLM so should be free from the elements. Hence, goods or services are offered and procedures for sale must be allowed, not syubhat and not opposed to Islamic principal.
\end{abstract}

Keywords: Multi Level Marketing (MLM), Business, Islamic Principal.

\begin{abstract}
ABSTRAK
Secara realita, kini perusahaan MLM sudah banyak tumbuh dan berkembang baik di dalam maupun luar negeri. Bahkan di Indonesia sudah ada yang secara terang-terangan menyatakan bahwa MLM tersebut sesuai syariat dan mendapatkan sertifikasi halal dari Dewan Syariah Nasional Majelis Ulama Indonesia (DSN-MUI). Sistem perdagangan Multi Level Marketing (MLM) dilakukan dengan cara menjaring calon nasabah yang sekaligus berfungsi sebagai konsumen dan member dari perusahaan yang melakukan praktek MLM. Islam mempunyai prinsip-prinsip tentang pengembangan sistem bisnis yaitu harus terbebas dari unsur dharar (bahaya), jahalah (ketidakjelasan) dan zhulm (merugikan atau tidak adil terhadap salah satu pihak). Oleh karena itu, sistem pemberian bonus harus adil, tidak menzalimi dan tidak hanya menguntungkan orang yang di atas. Bisnis juga harus terbebas dari unsur Maysir (judi), Gharar (penipuan), Haram, Riba (bunga) dan Bathil. Sehingga jika kita ingin melakukan bisnis MLM maka harus terbebas dari unsur-unsur tersebut. Oleh karena itu, barang atau jasa yang dibisniskan serta tata cara penjualannya harus halal, tidak syubhat dan tidak bertentangan dengan prinsip-prinsip syari'ah.
\end{abstract}

Kata kunci: Multi Level Marketing (MLM), Bisnis, prinsip syariah.

\section{PENDAHULUAN}

Salah satu pola bisnis yang saat ini sangat marak adalah bisnis Multi Level Marketing (MLM) yang merupakan salah satu cabang dari direct selling yaitu salah satu sistem bisnis yang pemasaran produknya menggunakan konsumen, pemasar, promotor dan sekaligus distributor. Multi Level Marketing adalah jaringan pemasaran berjenjang 
satu sistem pemasaran yang dirancang untuk dapat memberikan kesempatan kepada setiap orang agar dapat menjalankan setiap usahanya sendiri. Setiap orang yang bergabung dalam sistem network marketing ini berkesempatan mengembangkan usahanya dengan cara memakai dan menjual produk perusahaan serta mengajak orang lain yang disebut downline untuk bergabung.

Namun yang menjadi masalah adalah soal kehalalan dan kesucian produk, prosedur dan budaya kerjanya, apakah produk yang dijual bebas dari unsur-unsur yang diharamkan dalam Islam dan apakah cara kerjanya bebas dari unsur riba, gharar(tipuan atau ketidak pastian), maisir (judi) dan zulm (eksploitasi)? Maka penulis dalam tulisan ini akan berupaya memaparkan hal ini dengan menjelaskan apa yang dimaksud dengan bisnis Multi Level Marketing, dan pandangan Islam terhadap bisnis ini.

\section{DEFINISI DAN SISTEM KERJA MULTI LEVEL MARKETING}

Secara sederhana, yang dimaksud dengan Multi Level Marketing adalah suatu konsep penyaluran barang (produk/jasa tertentu) yang memberi kesempatan kepada para konsumen untuk turut terlibat sebagai penjual dan menikmati keuntungan di dalam garis kemitraannya/sponsorisasi (Pedoman Mitra Niaga, 1997:25).

Dalam pengertian yang lebih luas, Multi Level Marketing adalah salah satu bentuk kerja sama di bidang perdagangan/pemasaran suatu produk/jasa yang dengan sistem ini diberikan kepada setiap orang kesempatan untuk mempunyai dan menjalankan usaha sendiri. Kepada setiap orang yang bergabung dapat mengkonsumsi produk dengan potongan harga, serta sekaligus dapat menjalankan kegiatan usaha secara sendiri dengan cara menjual produk/jasa dan mengajak orang lain untuk ikut bergabung dalam kelompoknya. Setiap orang yang berhasil diajak dan bergabung dalam kelompoknya akan memberikan manfaat dan keuntungan kepada yang mengajaknya, lazimnya dengan memakai sistem persentase atau bonus (Lubis \& Wajdi, 2012).

Multi Level Marketing atau Direct Selling merupakan penyaluran dari produsen langsung ke konsumen, melalui distributor-person-person anggota MLM dan ini merupakan fungsi saluran distribusi yang berlaku di dunia marketing dalam bisnis. Bisnis model penyaluran seperti ini pula dapat disebut sebagai "Selling door to door", yaitu 
penjualan yang dilakukan oleh produsen langsung ke konsumen dengan mengerahkan salesman nya ke rumah-rumah atau ke kantor-kantor konsumen (Angipora, 1999).

Sistem perdagangan Multi Level Marketing (MLM) dilakukan dengan cara menjaring calon nasabah yang sekaligus berfungsi sebagai konsumen dan member dari perusahaan yang melakukan praktek MLM. Secara rinci, sistem perdagangan Multi Level Marketing dilakukan dengan cara sebagai berikut:

1. Mula-mula pihak perusahaan berusaha menjaring konsumen untuk menjadi member dengan cara mengharuskan calon konsumen membeli paket produk perusahaan dengan harga tertentu.

2. Dengan membeli paket produk perusahaan tersebut, pihak pemberi pembeli diberi satu formulir keanggotaan (member) dari perusahaan.

3. Sesudah menjadi member, maka bertugas berikutnya adalah mencari calon member-member baru dengan cara seperti diatas, yakni membeli produk perusahaan dan mengisi formulir keanggotaan.

4. Para member baru juga bertugas mencari calon member-member baru lagi dengan cara seperti diatas, yakni membeli produk perusahaan dan mengisi formulir keanggotaan.

5. Jika member mampu menjaring member-member baru yang banyak, maka ia akan mendapat bonus dari perusahaan. Semakin banyak member yang dapat dijaring, maka semakin banyak pula bonus yang akan didapatkan, Karena perusahaan merasa diuntungkan oleh banyaknya member yang sekaligus menjadi konsumen paket produk perusahaan.

6. Dengan adanya member baru yang sekaligus menjadi konsumen paket produk perusahaan, Maka member yang berada pada level pertama (member awal/ pelopor) Kedua dan seterusnya akan selalu mendapatkan bonus secara estafet dari perusahaan karna perusahaan merasa diuntungkan dengan adanya membermember baru sekaligus menjadi konsumen paket produk perusahaan.

Untuk lebih jelasnya bentuk usaha ini secara sederhana dapat diterangkan dengan ilustrasi berikut :

Misalnya sebuah PT. Sinar Mentari-Net sebuah perusahaan yang memasarkan produk/jasa dengan sistem network marketing telah menjaring si Ahmad sebagai 
anggota diharapkan pula dapat menjaring anggota-anggota baru untuk masuk dalam kelompoknya, misalnya B dan C. Selanjutnya, B dan C berusaha pula memperluas jaringannya, seperti $\mathrm{B}$ telah menjaring $\mathrm{D}, \mathrm{E}$, dan $\mathrm{F}$, sedangkan $\mathrm{C}$ telah menjaring $\mathrm{G}, \mathrm{H}$, I, J, K, L. Selanjutnya, D, E, dan F (grup dari B) dan H, I, J, K, L (grup dari C) akan berusaha pula untuk memperluas jaringannya dengan cara mencari anggota baru, demikian seterusnya.

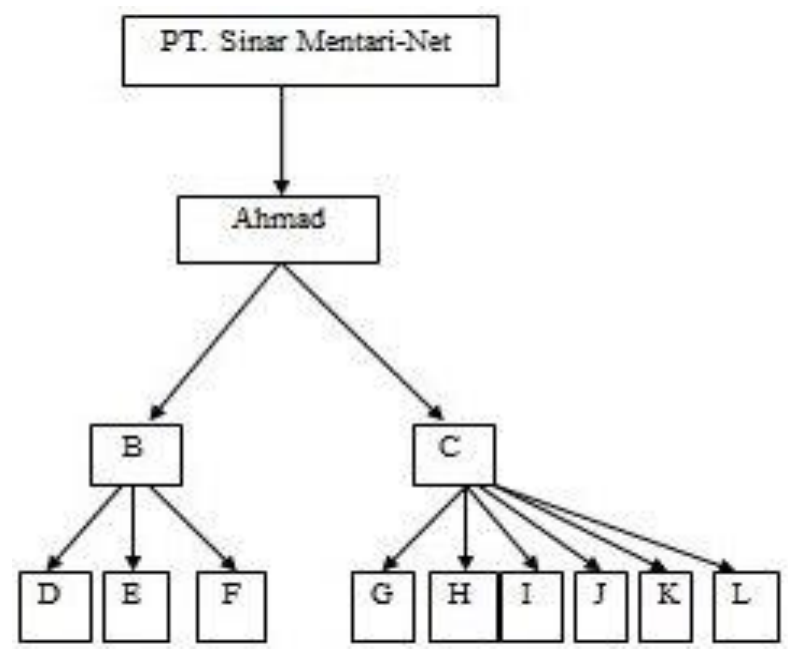

Dari perluasan dan pengembangan jaringan di atas, Ahmad akan memperoleh keuntungan berupa komisi, apakah berupa keuntungan langsung, komisi rabat (potongan harga), komisi pengembangan grup dan bentuk keuntungan lainnya sesuai dengan kebijaksanaan perusahaan. Jelasnya, semakin banyaknya dan berkembangnya grup Ahmad, begitu juga D, E, F (grup B) dan G, H, I, J, K, L (grup C) dan seterusnya anggotaanggota lain. Tegasnya, semakin besar akumulasi penjualan kelompok, semakin besar pula keunt ungan yang diperoleh.

\section{MULTI LEVEL MARKETING DALAM PERSPEKTIF SYARIAH}

Multi Level Marketing (MLM) dalam literatur fiqh Islam masuk dalam pembahasan Fiqh Muamalah disebutkan dalam bab Buyu' (perdagangan). Sehingga, tidak ada nash yang langsung mengarah kepadanya. Namun, ada beberapa nash yang mengarah kepadanya, baik Al-Qur'an, As-Sunnah, maupun kaidah fiqh, antara lain: Surat Al- Baqarah ayat 275 yang artinya; "Dan Allah telah menghalalkan jual beli dan dan mengharamkan riba". Surat Al-Maidah ayat 2 yang artinya; "Dan tolongmenolonglah kamu dalam (mengerjakan) kebajikan dan takwa, dan jangan tolong- 
menolong dalam berbuat dosa dan permusuhan”. Surat An-Nisa' ayat 29 yang artinya "Hai orang-orang yang beriman! Janganlah kamu saling memakan harta sesamamu dengan jalan yang batil(tidak benar), kecuali dalam perdagangan yang berlaku atas dasar suka sama suka di antara kamu. Dan janganlah kamu membunuh dirimu. Sungguh, Allah Maha Penyayang kepadamu."

Hukum dari bisnis Multi Level Marketing (MLM) yaitu diperbolehkan selama bisnis tersebut bebas dari riba (permainan bunga), zhulm (merugikan atau tidak adil terhadap salah satu pihak), gharar (penipuan), dharar (bahaya), jahalah (tidak transparan/ketidakjelasan) dan maysir (perjudian atau arisan berantai). Dalam surat alMaidah ayat 2 dijelaskan bahwa bisnis Multi Level Marketing (MLM) itu diperbolehkan apabila mengandung unsur tolong-menolong terhadap sesama manusia. Selain itu, dalam Surat An-Nisa ayat 29 telah mengingatkan bahwa dalam perdagangan dilakukan atas dasar suka sama suka dan tidak saling memakan harta sesama dengan jalan yang batil (tidak benar).

Adapun dari As-Sunnah yaitu:

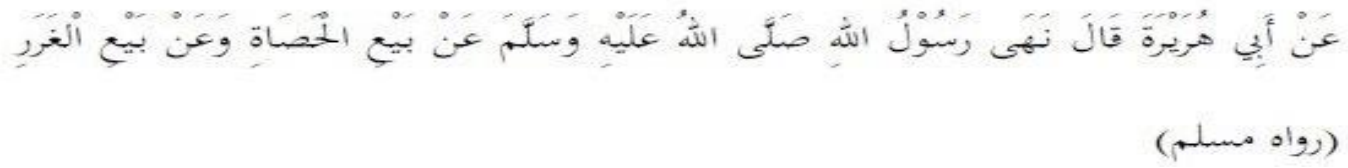

Dari Abu Hurairah, Rasulullah SAW melarang jual beli dengan cara melempar krikil kepada barang yang dibelinya dan melarang menjual barang yang tidak jelas rupa dan sifatnya (bai' al-gharar). (HR. Muslim).

Hadits diatas mengisyaratkan bahwa dalam perdagangan atau perniagaan diprioritaskan untuk menghindari pola sistem perniagaan yang riskan terhadap perilaku jual beli yang mengandung gharar dan kegiataan perdagangan atau perniagaan yang bermaksud untuk menipu orang lain demi mengeruk keuntungan dan kepuasaan materi secara pribadi.

Adapun dari Kaidah Fiqh Islam memberi kesempatan luas perkembangan bentuk dan macam jual beli sesuai dengan perkembangan hidup masyarakat. Kebolehan yaitu dikarenakan asalnya tidak ada dalil yang menunjukkan terhadap perubahannya (pelarangan). Sesuai dengan kaidah fiqh dibawah ini:

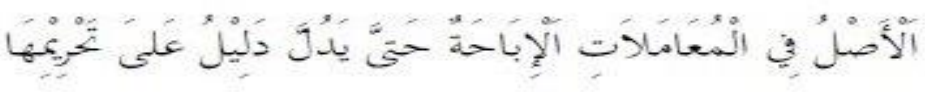


Pada dasarnya segala hukum dalam muamalah adalah boleh, kecuali ada dalil/prinsip yang melarangnya. ${ }^{1}$

Jadi pada dasarnya hukum dari MLM ini adalah mubah berdasarkan kaidah Ushuliyah tersebut. Selain itu bisnis ini bebas dari unsur-unsur Riba (sistem bunga), gharar (penipuan), dharar (bahaya), jahalah (tidak transparan) dan zhulm (merugikan orang lain) dan yang lebih urgen adalah produk yang dibisniskan adalah halal. Karena bisnis MLM merupakan bagian dari perdagangan oleh sebab itu bisnis ini juga harus memenuhi syarat dan rukun sahnya sebuah perikatan.

Secara realita, kini perusahaan MLM sudah banyak tumbuh dan berkembang baik di dalam maupun luar negeri. Bahkan di Indonesia sudah ada yang secara terang-terangan menyatakan bahwa MLM tersebut sesuai syariat dan mendapatkan sertifikasi halal dari Dewan Syariah Nasional Majelis Ulama Indonesia (DSN-MUI). Untuk MLM yang berdasarkan prinsip syariah ini, masih diperlukan akuntabilitas dari MUI.

pada bisnis multi level marketing yang dipakai oleh perusahaan-perusahaan terdapat dua masalah fiqih yang mengganjal bisnis MLM, yakni;

1. Posisi Upline dan Downline

Fakta yang terjadi dalam MLM adalah adanya penerimaan bonus oleh upline, sebagai imbalan atas prestasi downline-nya. Ini berarti, pihak upline menikmati suatu kemanfaatan yang bukan dari usahanya sendiri. Prestasi yang dilakukan downline akan secara otomatis mengakibatkan keuntungan upline-nya. Padahal, bisa jadi, antara upline dan downline tidak saling kenal dan tidak tahu aktifitasnya. Apalagi bagi upline yang downline-nya sudah banyak, dia bisa sama sekali tidak tahu menahu mengenai downlinenya. Tahu-tahu sudah untung dan bonusnya terus bertambah. MLM pasti selalu mengharuskan adanya pihak downline yang dirugikan untuk keuntungan upline - upline yang berada diatasnya. Terlepas dari apakah downline ini kemudian akan mencari 'mangsa' lain agar bisa naik jadi upline sehingga yang menderita kerugian adalah yang dibawahnya atau tidak. Padahal Islam tidak pernah mengajarkan demikian, karena setiap orang hanya berhak mendapatkan imbalan sesuai dengan apa yang dilakukannya. Dalam Surat Al-Muthaffifiin: 26 Allah SWT berfirman yang artinya: "Dan untuk (memperoleh kenikmatan surga dan macam-macamnya) itu hendaknya orang berlomba-lomba”. Dan

\footnotetext{
${ }^{1}$ Ibnu Qayyim al-Jauziyah, I'lamul Muwaqi'ien (Beirut: Daar Al-Fikr,t.th.), Juz I, 344.
} 
Allah SWT juga berfirman dalam Surat An-Najm: 39 yang artinya; "dan bahwasanya seorang manusia tiada memperoleh selain apa yang telah diusahakannya”. Berdasarkan ayat ini, setiap orang muslim hendaknya bekerja keras unt uk berusaha, dan mendapatkan keuntungan dari jerih payahnya sendiri (Syafe'i, 2001).

Dalam MLM, setiap downline harus bekerja keras agar ia menempati posisi tertentu jika ia ingin mendapatkan keuntungan. Karena, apabila ia berada dalam posisi paling bawah, dia tidak diuntungkan dengan keuntungan atau bonus apapun. Padahal, keberadaan orang paling bawah seperti ini adalah sebuah keniscayaan yang pasti ada dalam sebuah MLM.

\section{Dua Akad dalam Satu Akad}

Ada MLM yang membuka pendaftaran keanggotaan (member), dengan mensyaratkan kepada member untuk membayar sejumlah uang tertentu untuk menjadi member dan setelah menjadi member, ia akan menerima suatu produk tertentu yang diberikan oleh pihak perusahaan. Ini berarti, terjadi pembayaran dari satu pihak yang kemudian diikuti oleh pemberian barang dari pihak lainnya, sehingga terjadi akad bai' (jual beli). Selain itu, dia secara otomatis mendapat kesempatan untuk mencari orang yang akan menjadi downline-nya.

Jika dia berhasil mencari sejumlah downline (sesuai kesepakatan dengan perusahaan), maka dia berhak atas bonus dari perusahaan. Pencarian orang ini sifatnya tidak mengikat, artinya si member tidak berkewajiban untuk itu, hanya sebatas berhak saja. Bila ingin mendapatkan bonus, maka tentu dia harus mencari downline, tapi bila tidak juga tidak apa-apa. Hal seperti ini menimbulkan akad ju'alah.

Dalam MLM tipe ini, terjadi dua akad dalam waktu yang bersamaan: akad bai' dan akad ju'alah. Bai' berarti jual beli, sedangkan jualah berarti memberkan upah kepada seseorang yang telah melakukan pekerjaan untuknya (Madani, 2012). Jual beli diartikan juga dengan menukar barang dengan barang atau barang dengan uang dengan jalan melepaskan hak milik dari yang satu kepada yang lain atas dasar saling merelakan (Suhendi, 2010).

Imam Ahmad meriwayatkan sebuah hadits dari 'Abdullah bin Mas'ud ra, bahwasanya ia berkata:

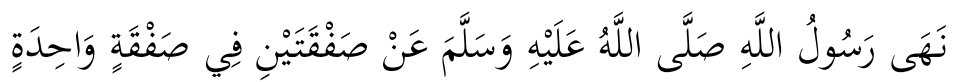


"Rasulullah $S A W$ melarang dua aqad dalam sebuah aqad jual beli. "(HR. Imam Ahmad).

Di dalam riwayat lain dituturkan, bahwasanya Abu Hurairah berkata:

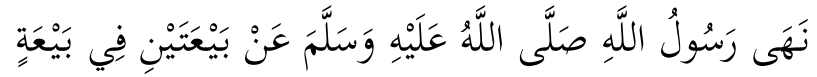

"Rasulullah SAW telah melarang dua aqad jual beli dalam satu aqad jual beli." (HR. at-Turmidzi)

Pembelian disini, berarti transaksi. Sedangkan dua pembelian ini berarti akad. Artinya, dilarang melakukan dua akad dalam stau transaksi. MLM jelas mempraktekkan dua akad dalam satu transaksi, yaitu bai' dan ju'alah.

Bahkan, ada sebagian madzhab Hanafiyyah, tidak diperbolehkan akad ju'alah, karena mengandung unsur gharar didalamnya. Yakni ketidakjelasan atas pekerjaan dan jangka waktu yang ditentukan. Hal ini ketika dianalogikan (qiyas) dengan akad ijarah yang mensyaratkan adanya kejelasan atas pekerjaan, upah dan jangka waktu (Djuwani, 2010).

Dari sisi akad, ada beberapa MLM yang bai'-nya terancam rusak (fasid). Ini terjadi pada beberapa MLM yang mensyaratkan pembelian produk untuk menjadi member, tapi pada prakteknya justru seperti jual beli. Calon member membayar biaya pendaftaran dan perusahaan memberinya produk tertentu, sehingga secara lahiriah adalah jual beli. Tapi calon member ketika memberikan uang tidak berniat membeli barang melainkan niatnya adalah menjadi member, sehingga ijab dari pihak member ini kabur. Maka dari itu, jual belinya fasid, karena salah satu rukunnya tidak jelas. Selain itu, calon member juga harusnya tidak melakukan akad dengan terpaksa. Artinya jika niatnya menjadi member, seharusnya calon member tidak menyesal jika ternyata ia harus membeli produk tertentu dari perusahaan tersebut.

Suka sama suka itu tidak dapat diketahui dengan jelas kecuali melalui perkataan, karena perasaan suka itu bergantung pada hati masing-masing. Ini pendapat kebanyakan ulama. Tetapi, Nawawi, Mutawali, Bagawi, dan beberapa ulama lain berpendapat bahwa lafadz itu tidak menjadi rukun, hanya adat kebiasaan saja. Apabila menurut adat kebiasaan seperti itu telah dipandang sebagai jual beli, itu saja sudah cukup karena tidak ada suatu dalil yang jelas untuk mewajibkan lafadz (Rasyid, 2012).

Ada juga MLM yang didalamnya terjadi “akad membership" dan ju'alah, hukumnya tidak berbeda dengan MLM tipe pertama. Pendaftaran keanggotaan dalam MLM tipe ini harus dipandang sebagai suatu akad tersendiri, karena telah memenuhi 
unsur-unsur suatu akad. Persoalan sah tidaknya akad seperti ini adalah persoalan lain. Yang pasti, dalam MLM tipe kedua telah terjadi dua akad, akad membership dan akad ju'alah, sehingga bisa dipersamakan dengan MLM tipe pertama. Sementara itu, ada pula MLM di dalamnya telah terjadi akad yang tidak jelas obyeknya, karena bukan barang atau jasa, melainkan kesempatan untuk mendapat bonus jika nantinya si member membeli produk perusahaan tempat ia mendaftar.

Dapat dilihat bahwa dalam MLM terdapat dua akad dalam satu transaksi atau “bai'atain fi bai'atin" dan akad yang tidak pasti status hukumnya atau batil. Maka dari itu, karena dalam bisnis MLM terjadi akad yang mengandung kerancuan, bisnis ini potensial bagi terjadinya gharar.

Mengenai makelar di atas makelar atau dua aqad dalam satu aqad, banyak orang muslim yang mengklaim bahwa bisnis MLM itu halal dikarenakan adanya tali silaturrahmi di antara anggota atau member di perusahaan tersebut, atau adanya pembelajaran dalam berdagang, dan lain sebagainya. Namun untuk itu semua, tetaplah harus meninjau hal-hal yang lain. Maka dapat digunakan di sini kaidah :

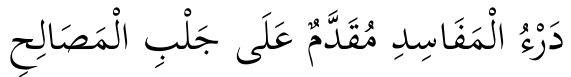

Artinya: "Menolak kerusakan itu didahulukan daripada mengambil kemaslahatan"

DSN MUI sudah mengeluarkan fatwa tentang MLM dengan nama Penjualan Langsung Berjenjang Syariah No 75 Tahun 2009.. DSN MUI menetapkan sebagai berikut:

a. Ada obyek transaksi riil yang diperjualbelikan berupa barang atau produk jasa.

b. Barang atau produk jasa yang diperdagangkan bukan sesuatu yang diharamkan dan atau yang dipergunakan untuk sesuatu yang haram.

c. Transaksi dalam perdagangan tersebut tidak mengandung unsur gharar, maysir, riba, dharar, dzulm, maksiat.

d. Tidak ada harga/biaya yang berlebihan (excessive mark-up), sehingga merugikan konsumen karena tidak sepadan dengan kualitas/manfaat yang diperoleh.

e. Komisi yang diberikan oleh perusahaan kepada anggota baik besaran maupun bentuknya harus berdasarkan pada prestasi kerja nyata yang terkait langsung 
dengan volume atau nilai hasil penjualan barang atau produk jasa, dan harus menjadi pendapatan utama mitra usaha dalam PLBS.

f. Bonus yang diberikan oleh perusahaan kepada anggota (mitra usaha) harus jelas jumlahnya ketika dilakukan transaksi (akad) sesuai dengan target penjualan barang dan atau produk jasa yang ditetapkan oleh perusahaan.

g. Tidak boleh ada komisi atau bonus secara pasif yang diperoleh secara reguler tanpa melakukan pembinaan dan atau penjualan barang dan atau jasa.

h. Pemberian komisi atau bonus oleh perusahaan kepada anggota (mitra usaha) tidak menimbulkan ighra'.

i. Tidak ada eksploitasi dan ketidakadilan dalam pembagian bonus antara anggota pertama dengan anggota berikutnya.

j. Sistem perekrutan keanggotaan, bentuk penghargaan dan acara seremonial yang dilakukan tidak mengandung unsur yang bertentangan dengan aqidah, syariah dan akhlak mulia, seperti syirik, kultus, maksiat dan lain-lain.

k. Setiap mitra usaha yang melakukan perekrutan keanggotaan berkewajiban melakukan pembinaan dan pengawasan kepada anggota yang direkrutnya tersebut.

1. Tidak melakukan kegiatan money game.

Hal-hal yang perlu diperhatikan dalam sistem operasionalisasi multi level marketing syariah (Lubis \& Wajdi, 2012), adalah:

a. Sistem distribusi pendapatan, harus dilakukan secara proporsional dan seimbang. Dengan kata lain, tidak terjadi eksploitasi antar sesama.

b. Apresiasi distributor, harus apresiasi yang sesuai dengan prinsip-prinsip islam. Misalnya, tidak melakukan pemaksaan, tidak berdusta, jujur, dan tidak merugikan pihak lain, serta berakhlakul karimah.

c. Penetapan harga, kalaupun keuntungan (komisi dan bonus) yang akan diberikan kepada para anggota berasal dari keuntungan penjualan barang, bukan berarti harga barang yang dipasarkan harus tinggi, hendaknya semakin besar jumlah anggota dan distributor maka tingkat harga menurun, yang pada akhirnya kaum muslimin dapat merasakan sistem pemasaran tersebut. 
d. Jenis produk yang ditawarkan haruslah produk yang benar-benar terjamin kehalalan dan kesuciannya sehingga kaum muslimin merasa aman untuk menggunakan/mengkonsumsi produk yang dipasarkan.

Apabila di dalam sebuah MLM itu ternyata terdapat indikasi riba, misalnya dalam memutar dana yang terkumpul. Atau ada indikasi terjadinya gharar atau penipuan baik kepada downline ataupun kepada upline. Atau mungkin juga terjadi dhararyaitu hal-hal yang membahayakan, merugikan atau mendzalimi pihak lain, entah dengan mencelakakan dan menyusahkan. Dan tidak tertutup kemungkinan ternyata ada unsur jahalah atau ketidaktransparanan dalam sistem dan aturan. Atau juga perdebatan sebagian kalangan tentang haramnya samsarah 'ala samsarah (pemakelaran). Sehingga ketika masuk ke bisnis Multi Level Marketing hendaklah berhati-hati, diteliti terlebih dahulu bagaimana sistem yang berjalan dalam bisnis tersebut, karena dikhawatirkan akan masuk ke bisnis yang diharamkan.

\section{KESIMPULAN}

Berdasarkan dari pembahasan di atas, maka dapat diambil kesimpulan yaitu Multi Level Marketing adalah salah satu bentuk kerja sama di bidang perdagangan/pemasaran suatu produk/jasa yang dengan sistem ini diberikan kepada setiap orang kesempatan untuk mempunyai dan menjalankan usaha sendiri. Sistem perdagangan Multi Level Marketing (MLM) dilakukan dengan cara menjaring calon nasabah yang sekaligus berfungsi sebagai konsumen dan member dari perusahaan yang melakukan praktek MLM. Sistem kerja MLM yang sesuai syariah menurut al-Quran dan al-hadits yaitu terhindar dari unsur-unsur haram seperti riba', gharar, dharar, dan jahalah

\section{DAFTAR PUSTAKA}

Angipora, M. P. (1999). Dasar-Dasar Pemasaran. Jakarta: PT. Raja Grafindo Persada. Djuwani, D. (2010). Pengantar Fiqh Mu'amalah. Yogyakarta: Pustaka Pelajar.

Lubis, S. K., \& Wajdi, F. (2012). Hukum Ekonomi Islam. Jakarta: Sinar Grafika. Madani. (2012). Fiqh Ekonomi Syari'ah. Jakarta: Kencana.

Rasyid, S. (2012). Fiqh Islam (Hukum Fiqh Lengkap). Bandung: Sinar Baru Algensindo. 
AL-'ADALAH: Jurnal Syariah dan Hukum Islam

e-ISSN: 2503-1473

Hal. 167-178

Vol. 2, No. 3, November 2017

Suhendi, H. (2010). Fiqh Muamalah. Jakarta: Rajawali Pres.

Syafe'i, R. (2001). Fiqh Muamalah. Bandung: Pustaka Setia. 